\title{
ON PRESERVATION AND DEVELOPMENT OF ESTONIAN AS A RESEARCH LANGUAGE IN ANTHROPOLOGY - THE ROLE OF THE YEARBOOKS OF THE ESTONIAN ANTHROPOMETRIC REGISTER (1998-2002) IN IT. PART III
}

\author{
JaAn Kasmel, Tiiu Kasmel \\ Centre for Physical Anthropology, University of Tartu, Tartu, Estonia
}

\begin{abstract}
On 18 July 2018, the Centre for Physical Anthropology at the University of Tartu marked its 25th anniversary. The specialists of different research areas from whole Estonia who had gathered around the Centre also considered it necessary to preserve and develop Estonian as a research language in anthropology. When cooperation was established with the Estonian Anthropometric Register (founded in 1995), it became possible to publish the Estonianlanguage Yearbook of the Estonian Anthropometric Register (YEAR), the first of which was published in 1998, i.e. 20 years ago.

The article deals with the YEARs published in 1998-2002 - who were the authors who decided to publish their research papers on anthropology in Estonian in this serial, how many of them there were, in which towns and institutions they worked?

The first part of the overview briefly described the publications by anthropologists originating in Estonia, starting with publications in Latin and finishing with English as the main present-day language of research. Table 1 provided a general characterisation of the five yearbooks and Table 2 the distribution of the published articles according to the number of authors.

Tables 3-7 in the second part of the overview presented the distribution of articles over the years according to their first authors. Table 8 presented the distribution of authors between Tartu and Tallinn, and the institutions and their subunits in these towns according to the first authors of the articles.

Table 9 in the next, third part of the overview enables us to establish who were the researchers who participated in the YEARs as co-authors of the
\end{abstract}


articles published in Estonian: at which article in which YEAR they were co-authors; their rank in the order of co-authors; at which institution or its subunit they worked at that time, and at how many articles in total they published as co-author in the five YEARs.

Keywords: Centre for Physical Anthropology at the University of Tartu; Yearbooks of the Estonian Anthropometric Register; Estonian as a research language in anthropology

\section{PART III}

The first and the second part of the overview on this theme were published in the journal Papers on Anthropology, respectively in issue XXVI/1, 2017 (pp. 28-40) [6] and in issue XXVII/1, 2018 (pp. 23-35) [7]. Here, we present its third part.

According to the tables of contents of Yearbooks of the Estonian Anthropometric Register 1998-2002 [1, 2, 3, 4, 5], Table 9 was compiled, which shows the participation of researchers as co-authors of articles published in Estonian.

In the table of contents of YEAR 1998 [1], we can see that the collection includes 27 articles, of which 11 articles have only one author. 16 articles have two or more authors. The table of contents of this collection shows that the second article has two authors, the first of them is the first author and the second, thus, the co-author. The third article has six authors, of which the one mentioned first is the first author, and the other five authors are co-authors; according to their order, they can be considered the second, third, fourth, fifth and sixth author respectively.

Accordingly, we started compiling Table 9 as follows. After number 1, we write the initial of the co-author of the first article with two authors, which is followed by the surname of the co-author, and thereafter a colon. This is followed by the year of publication of the Yearbook, here 1998, followed by a hyphen, then the number of the article with several authors in the table of contents, here 2, a hyphen, the number of the co-author in the ranking of authors of the article, here 2 , a hyphen, the institution where the co-author works, a hyphen and its subunit, then a semicolon.

The University of Tartu is abbreviated as UT; this is followed by a hyphen and then the subunit of the university with the number given in Table 8 [7]. If the workplace of the co-author is Tartu University Hospital, it is abbreviated as TUH, which is followed by a hyphen and the number of the hospital subunit in Table 8 [7]. 
Table 8 in the second part of the overview shows the distribution of first authors between Tartu and Tallinn. The institutions of Tartu represented there are the University of Tartu with 14 subunits, Tartu University Hospital with 7 subunits, the Baer Museum and the Estonian Naturalists' Society.

In the current part, the new subunit of the University of Tartu as the workplace of co-authors is the Institute of Public Health (15); the subunit of Tartu University Hospital - United Laboratories (8); new workplaces are the Research Centre of Top-Level Sports and Tartu Midtown School.

Table 8 includes 7 institutions from Tallinn; now Tallinn Pedagogical University and Sports Medicine Foundation have been added. When presenting the workplaces of co-authors from Tallinn, the names given in Table 8 have been used, in some cases they have been abbreviated, e.g. Estonian Institute of Cardiology - EIC.

If this co-author has published more articles in the Yearbooks as a coauthor, corresponding entries have been made after his/her name according to the same scheme. When entries about the co-authors of all yearbooks have been entered into Table 9, we sum up, after the last semicolon the contribution of each co-author to the articles of all the Yearbooks; after the equal sign the number of articles is given to which this person has contributed as a co-author.

Table 9. Co-authors of articles published in YEARs in 1998-2002

1. H. Kaarma: 1998-2-2-UT-7; 1998-23-2-UT; 1999-12-2-UT-7; 1999-14-3-UT-7; 2000-8-2UT-7; 2001-15-2-UT-7; 2001-17-2-UT-7; 2002-1-2-UT-7; 2002-12-2-UT-7; =9.

2. J. Peterson: 1998-3-2-UT-7; $=1$.

3. J. Kasmel: 1998-3-3-UT-7; $=1$.

4. G. Veldre: 1998-3-4-UT-7; $=1$.

5. K. Saluvere: 1998-3-5- Estonian Ministry of Social Affairs; $=1$.

6. L. Saluste: 1998-3-6-UT-7; 1998-10-4-UT-7; 1998-12-3-UT-7; 1998-23-4-UT; 1999-12-3UT-7; 1999-14-4-UT-7; 2000-8-3-UT-7; 2001-15-3-UT-7; 2001-17-4-UT-7; 2002-12-3-UT-7; $=10$.

7. S. Täll: 1998-8-2-TUH-5; 2001-19-4-Research Centre of Top-Level Sports; =2.

8. N. Ignatjeva: 1998-8-3-TUH-5; 2002-3-6-TUH-5; =2.

9. J. Liivamägi: 1998-10-2-TUH-4; 1998-12-2-TUH-4; $=2$.

10. A. Aluoja: 1998-10-3-TUH-4; $=1$.

11. S. Koskel: 1998-10-5-UT-9; 1998-12-4-UT-9; 1998-19-3-UT; 1999-19-3-UT; 2000-12-2-UT9; 2000-16-3-UT-13; 2001-20-6-UT-9; 2002-1-3-UT-9; 2002-20-2-UT-9; 2002-21-3-UT-9; $=10$.

12. K. Lilienberg: 1998-14-2-Estonian Institute of Cardiology (EIC); 1998-16-3-EIC; =2.

13. L. Tšaiko: 1998-14-3-EIC; 1998-16-4-EIC; =2. 
14. R. Sink: 1998-14-4- EIC; $=1$.

15. E. Solodkaja: 1998-15-2-EIC; 1999-23-2-EIC; $=2$.

16. J. Abina: 1998-15-3-EIC; 1999-23-4-EIC; $=2$.

17. A. Olferjev: 1999-15-4-EIC; $=1$.

18. A. Tellmann: 1998-16-2-EIC; $=1$.

19. M. Stamm: 1998-19-2-Tallinn Pedagogical University (TPU); 1999-19-2-TPU; 2000-16-2TPU; 2001-20-2-TPU; 2002-21-2-TPU; =5.

20. M. Thetloff: 1998-21-2-Health Insurance Fund; 1999-5-2-UT-7; =

21. T. Kasmel: 1998-22-2-UT-7; 2000-5-2-UT-7; $=2$.

22. V. Loolaid: 1998-23-3-UT; 1999-14-2-UT-7; 2001-17-3-UT-7; =3.

23. T. Jürimäe: 1998-24-2-UT-13; 1998-25-2-UT-13; 1999-6-2-UT-13; 1999-7-2-UT-13; 199911-2-UT-13; 1999-16-2-UT-13; 2000-2-2-UT-13; 2000-11-3-UT-13; 2000-13-2-UT-13; 2000-14-2-UT-13; 2000-19-2-UT-13; 2001-2-3-UT-13; 2001-6-2-UT-13; 2002-4-2-UT-13; 2002-10-2-UT-13; =15.

24. T. Kaasik: 1998-24-3-UT-15; $=1$.

25. R. Aule: 1998-26-2-UT-8; 1999-13-2-UT-13; 2000-9-2-UT-8; 2001-16-2-UT-8; 2002-13-3$\mathrm{UT}-12 ;=5$.

26. T. Sikkut: 1998-26-3-UT-8; 1999-13-3-UT-13; 2000-9-3-UT-8; 2001-16-3-UT-8; 2001-19-5UT-13; $=5$.

27. A. Viru: $1998-26-4-U T-8 ;=1$.

28. J. Ereline: 1998-26-5-UT-8; 2002-3-3-UT-11; 2002-16-2-UT-11; 2002-17-3-UT-11; =4.

29. M. Laurits: $1998-27-2-U T-14 ;=1$.

30. E. Pihl: 1999-6-3-UT-13; 2000-11-4-UT-13; 2000-14-4-UT-13; 2001-2-2-UT-13; =4.

31. T. Sööt: 1999-7-3-UT-13; 2002-10-4-UT-13; =2.

32. A. Leppik: 1999-7-4-UT-13; 2000-3-2-UT-13; 2001-7-5-UT-13; =3.

33. L. Suurorg: 1999-8-2-Tallinn Nõmme Children's Hospital; 2002-6-2- Tallinn Children's Hospital; $=2$.

34. K. Puss/Õun: 1999-9-2-UT-7; 2000-4-2-UT-7; 2000-6-2-UT-7; 2001-10-2-UT-7; =4.

35. J. Maaroos: 1999-10-2-TUH-5; 2002-9-3-TUH-5; $=2$.

36. J. Jürimäe: 1999-11-2-UT-13; 2000-3-3-UT-13; 2000-11-2-UT-13; 2000-14-3-UT-13; 20017-4-UT-13; 2002-5-4-UT-13; 2002-10-3-UT-13; =7.

37. R. Stamm: 1999-13-4-UT-13; 2000-9-4-UT-13; 2001-16-4-UT-8; =3.

38. V. Serkina: 1999-21-2-Institute of Experimental and Clinical Medicine; $=1$.

39. G. Goldsteine: 1999-23-3-EIC; $=1$.

40. R. Kaup: 1999-23-5-EIC; $=1$.

41. D. Listopad: $1999-23-6-E I C ;=1$.

42. T. Kaljuste: $1999-23-7-E I C ;=1$.

43. A. Dejev: $1999-23-8-E I C ;=1$.

44. T. Kõrge: $2000-2-3-U T-13 ;=1$.

45. V. Hussar: 2000-3-4-Tartu Midtown School; $=1$.

46. A. Ehrenberg: 2000-4-3-TUH-3; $=1$. 
47. L. Jannus: 2000-4-4-TUH-3; $=1$.

48. M. Saava: 2000-7-2-EIC; 2001-13-2-EIC; 2002-11-2-EIC; =3.

49. Ü. Kirss: $2000-8-4-U T-7 ;=1$.

50. V. Vasar: $2000-8-5-\mathrm{TUH}-4 ;=1$.

51. K. Tammik: 2000-14-5-UT-12; $=1$.

52. A. Gross: $2002-14-6-U T-13 ;=1$.

53. E. Rajavee: $2002-15-2-U T-3 ;=1$.

54. E. Sepp: 2002-1-2-UT-3; $=1$.

55. K. Sudi (Graz University, Austria): 2001-7-2; 2002-5-2; $=2$.

56. D. Payerl (Graz University, Austria): 2001-7-3; 2002-5-3; =2.

57. T. Bakler: 2000-18-2-TUH-1; $=1$.

58. A. Landõr: 2001-19-2-TUH-5; $=1$.

59. J. Loko: 2001-19-3-UT-13; 2001-20-5-UT-13; 2002-27-3-UT-13; =3.

60. K. Thomson: 2001-20-3-TPU; $=1$.

61. A. Nurmekivi: 2001-20-4-UT-13; $=1$.

62. P. Kaldmäe: 2001-21-2-Tallinn Nõmme Children's Hospital; $=1$.

63. E. Käärik: 2001-23-2-UT-9; $=1$.

64. M. Lintsi: 2002-1-4-UT-7; =1.

65. M. Proosa: 2002-3-2-UT-11; $=1$.

66. M. Pääsuke: 2002-3-3-UT-11; 2002-17-2-UT-11; =2.

67. H. Gapeyeva: 2002-3-5-UT-11; 2002-16-3-UT-11; 2002-17-4-UT-11; =3.

68. J. Vider: 2000-9-2-TUH-5; $=1$.

69. M. Lepik: 2002-9-4-Sports Medicine Foundation, Tallinn; $=1$.

70. T. Salum: 2002-9-5-TUH-8; $=1$.

71. M. Tannbaum: 2002-13-2-UT-12; $=1$.

72. H. Maamägi: 2002-16-4-UT-11; $=1$.

73. E. Indermitte: 2002-18-2-UT-15; $=1$.

74. A. Saava: $2002-18-3-$ UT-15; $=1$.

75. S. Tarraste: $2002-22-2-T a l l i n n$ Children's Hospital; $=1$.

76. M. Aaremäe: 2002-22-3-Tallinn Children's Hospital; $=1$.

77. K. Ilves: $2002-27-2-U T-13 ;=1$.

In YEAR 1998, 27 articles were published; 11 of them had one author; 16 articles had from two to six authors; i.e. there were 16 first authors and 39 co-authors.

In YEAR 1999, 24 articles were published; 10 of them had one author; 14 articles had from two to seven authors; i.e. there were 14 first authors and 30 co-authors. 
In YEAR 2000, 21 articles were published; 6 of them had one author; 15 articles had from two to six authors; i.e. there were 15 first authors and 32 co-authors.

In YEAR 2001, 26 articles were published; 12 of them had one author; 14 articles had from two to six authors; i.e. there were 14 first authors and 30 co-authors.

In YEAR 2002, 27 articles were published; 10 of them had one author; 17 articles had from two to six authors; i.e. there were 17 first authors and 40 co-authors.

In total 125 articles were published in YEARs 1998-2002; 49 of them had one author; 76 articles had from two to seven authors; i.e. there were 76 first authors and 171 co-authors.

125 first authors and 171 co-authors participated in writing the 125 articles published in YEARs in 1998-2002; thus, the total number of authors is 296.

The number of first authors - 125 - accounts for $42.2 \%$ of the total number of authors (296), and the number of co-authors is $57.8 \%$ of the total number of authors.

Table 9, Co-authors of articles published in YEARs in 1998-2002, shows that T. Jürimäe participated in writing of 15 articles, S. Koskel and L. Saluste both of 10 articles, H. Kaarma of 9 articles, J. Jürimäe of 7 articles, M. Stamm, R. Aule and T. Sikkut of 5 articles each. The names of these co-authors and their total number of articles have been printed in bold.

The other co-authors contributed to writing of fewer articles.

Table 9 enables us to find researchers, 77 persons in total, who participated as co-authors of articles published in Estonian in the YEARs - in which YEAR and at which article they were co-authors, at which institution or its subunit they worked at that time, and at how many articles in total this researcher was a co-author in the five YEARs.

All the authors of the articles published in Estonian in the five Yearbooks of the Estonian Anthropometric Register, both first authors of the articles and coauthors, should be thanked for doing their best to preserve and develop Estonian as a research language in anthropology, starting more than 20 years ago.

Time has passed on, and the Estonian research language in anthropology has developed. It should be wished that all the anthropologists who have gathered around the Centre for Physical Anthropology at the University of Tartu and the Anthropology Section of the Estonian Naturalists' Union would be willing to publish their works in Estonian, if possible, in an Estonianlanguage collection of papers on anthropology, and the Estonian language 
would remain fully capable of expressing scientific thought in anthropology as well.

\section{REFERENCES}

1. Eesti Antropomeetriaregistri Aastaraamat 1998 (1998). Tartu.

2. Eesti Antropomeetriaregistri Aastaraamat 1999 (1999). Tartu.

3. Eesti Antropomeetriaregistri Aastaraamat 2000 (2000). Tartu.

4. Eesti Antropomeetriaregistri Aastaraamat 2001 (2001). Tartu.

5. Eesti Antropomeetriaregistri Aastaraamat 2002 (2002). Tartu.

6. Kasmel J., Kasmel T. (2017). On preservation and development of Estonian as a research language in anthropology - the role of the Yearbooks of the Estonian Anthropometric Register (1998-2002) in it. Papers on Anthropology XXVI/1, $28-40$.

7. Kasmel J., Kasmel T. (2018). On preservation and development of Estonian as a research language in anthropology - the role of the Yearbooks of the Estonian Anthropometric Register (1998-2002) in it. Part II. Papers on Anthropology XXVII/1, 25-35.

\section{Address for correspondence:}

Jaan Kasmel

Centre for Physical Anthropology

University of Tartu

Struve 2, Tartu 51003, Estonia

E-mail: jaanjkasmel@hot.ee 